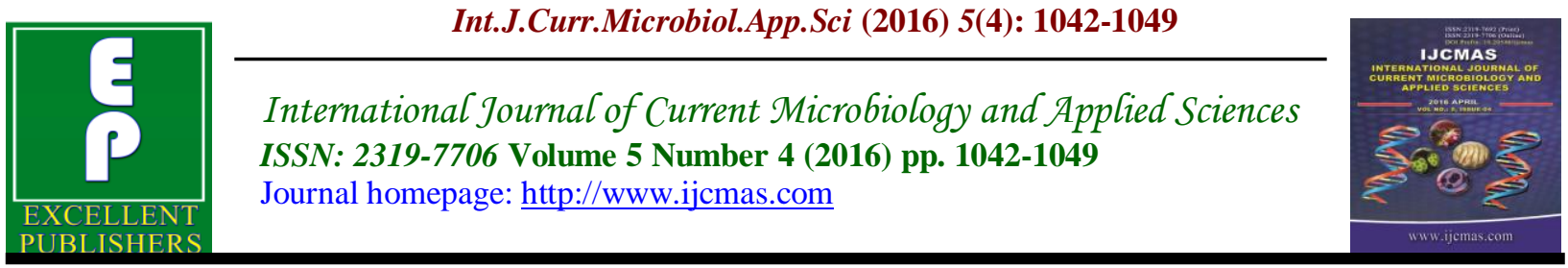

Original Research Article

http://dx.doi.org/10.20546/ijcmas.2016.504.119

\title{
Isolation and Biochemical Characterization of Lactobacillus species Isolated from Dahi
}

\author{
P. Kavitha*, D. Sindhuja and M. Banumathi \\ Department of Microbiology Srimad Andavan College, Tamilnadu, India \\ *Corresponding author
}

\begin{abstract}
A B S T R A C T
Keywords

Dahi (curd) is a fermented milk product, most commonly used by Indian population. Trials are in process to establish dahi as a source of health beneficial

Dahi, probiotics, Biochemical characterization, MRS agar

Article Info

Accepted:

18 February 2016

Available Online:

10 April 2016 organisms (probiotics). Hence, the present study is directed towards the study of prevalence of Lactobacillus species in dahi .A total of 40 samples of dahi were collected for the isolation of Lactobacilli using Lactobacillus selection MRS agar. Thirty-eight colonies were randomly picked based on colonial morphology. All the isolates were subjected to cell morphology, physiology and an array of biochemical characterization. The isolates showed different growth patterns at different temperatures $\left(15^{\circ} \mathrm{C}\right.$ and $\left.45^{\circ} \mathrm{C}\right)$, oxygen and at different concentrations of $\mathrm{NaCl}(2.0$, 4.0 and $6.5 \%$ ). On the basis of physiological tests and sugar utilization pattern, all the three isolates were confirmed to the different species of Lactobacillus: Lactobacillus acidophilus, Lactobacillus bulgaricus, Lactobacillus lactis. Among isolates, L. acidophilus was found to be prevalent in dahi.
\end{abstract}

\section{Introduction}

Generally, the healthiness of food has been linked to a nutritionally rich diet recommended by specialists and the role of it in totality has been emphasized instead of emphasizing on individual components.

Milk, very first food of mammals including humans, is surrounded with emotional and cultural importance in the society. Men have been habituated to think of milk as nature's most perfect food for them (1). Therefore, milk and dairy products have long been recognized as an important constituent of balanced diet for human beings as these products provide a wide range of essential nutrients.

The microbial ecology in the gastrointestinal tract influences many functions in our body (i.e., digestion, absorption of nutrients, detoxification and ultimately the functioning of immune system) (2,3). All these aspects make the gut a target organ for development of functional foods that can help in maintaining the relative balance of microorganisms in the gastrointestinal tract. The establishment of microbial balance by shifting it towards a beneficial one with the 
help of specific dietary components (i.e., probiotics and prebiotics) has opened the gateway for the development of functional foods ensuring more benefits to the host's health $(4,13,14)$.

Probiotics are defined as live microbes which transit the gastro-intestinal tract and in doing so, benefit the health of the consumer. Probiotic microorganisms are found in many food products, especially in the fermented foods. Therefore, the probiotic lactic acid bacteria can be isolated from the fermented milk products like acidophilus milk, yoghurt lactic cultures, is widely consumed throughout South Asia, especially in the Indian subcontinent. The micro-flora of dahi varies from one geographical region to the other and also with seasonal variations of the year. Apart from the starter lactic cultures, dahi can also have some probiotics like Lactobacillus acidophilus, Lactobacillus bulgaricus etc. Therefore, dahi can be used as a source for isolation of probiotic bacteria and also a product of immense importance for human consumption $(5,6)$.

\section{Materials and Methods}

\section{Isolation of Lactic Acid Bacteria}

Dahi samples (40) for the isolation of lactic acid bacteria were collected from different rural and urban locations in order to get a wider diversity of lactic acid bacterial strains. Each sample was taken in a sterile container separately and placed in a polyethylene bag during transportation to the laboratory employing standard conditions for sample collection. One gram of curd sample was immediately processed under aseptic conditions by suspending in $9 \mathrm{~mL}$ of normal saline $(0.85 \%)$ and was vortexed for proper mixing. One milliliter of each well-mixed dahi sample was enriched in $9 \mathrm{~mL}$ of sterile Lactobacillus selection
MRS broth for $24 \mathrm{~h}$ at $37^{\circ} \mathrm{C}$. Before inoculation of sample, the $\mathrm{pH}$ of MRS broth was adjusted to $6.5 \pm 0.2$. The enriched samples were streaked on the Petri plates containing Lactobacillus selection MRS agar with the help of calibrated inoculating loop and incubated aerobically at $37^{\circ} \mathrm{C}$ for $48 \mathrm{~h}$ and observed for the growth of colonies. and dahi. Dahi, naturally fermented milk by characterization of Lactobacilli isolates grown on MRS agar was done mainly with the help of the following tests microscopic examination (Gram staining), catalase test, growth at different temperatures $10+1^{\circ} \mathrm{C}$ and $42+1^{\circ} \mathrm{C}$ ), growth under aerobic and anaerobic conditions, growth at different $\mathrm{NaCl}$ concentration, fermentation of different carbohydrates, etc $(7,8,9,15,16)$.

\section{Microscopic Examination}

The purity morphological identification of the isolates as Lactobacilli was confirmed microscopically by performing Gram staining, for which single colony of each isolate was picked up and stained as per the standard protocol and viewed under oil immersion for similar type of cells.

\section{Micrometry}

Each isolate after Gram staining was subjected to microscopic measurements employing ocular and stage micrometer. To determine the size of Lactobacilli isolates, prepared slides were observed under oil immersion objective and number of ocular divisions occupied by each bacillus was recorded and interpreted as per the above formula.

\section{Physiological Characterization of Isolates}

After confirming the purity of culture, each isolate was further assessed for growth at two different temperatures. 


\section{Growth of Isolates at $\left(10^{\circ} \mathrm{C}\right.$ and $\left.42^{\circ} \mathrm{C}\right)$}

The isolates were tested for their ability to grow in MRS broth at $10+1^{\circ} \mathrm{C}$ for 7 days and $42^{\circ} \mathrm{C}$ by incubating for $24-48 \mathrm{~h}$. For this, $10 \mathrm{~mL}$ of MRS broth tubes were inoculated at $1 \%$ of Lactobacilli cultures. The

\section{Identification of Selected Lactobacilli}

The identification and further accordingly for the presence or absence of enzyme.

\section{Gas from Glucose}

Sterile test tubes of $10 \mathrm{~mL}$ glucose broth containing Durham's tube (inverted and dipped), were inoculated with Lactobacilli cultures at the at $1 \%$ and incubated at $37^{\circ} \mathrm{C}$ for 24-48h. Gas production that appeared in the form of a hollow space in Durham's tube was recorded as a positive result.

\section{Citrate Utilization Test}

The isolates were inoculated in Simmons citrate agar incubated at $37^{\circ} \mathrm{C}$ for $24 \mathrm{~h}$. After incubation, the appearance of blue coloration indicated the positive test for citrate utilization and was recorded accordingly for the isolates tested.

\section{Carbohydrate Fermentation Pattern by the Isolates}

Most microorganisms obtain their energy through a series of orderly and integrated enzymatic reactions leading to the biooxidation of a substrate, frequently a carbohydrate. Thus, different sugars were used for determining the fermentation profile and further characterization of Lactobacilli isolates. For this, Lactobacilli cultures were subjected to sugar fermentation reactions using CHL medium for knowing their fermentation pattern. CHL medium was used as basal medium. Four milliliter of the medium was taken in each tube and sterilized by autoclaving. One sugar disc was aseptically added to each tube. Each tube was inoculated with $0.1 \mathrm{~mL}$ of inoculum, incubated at $37^{\circ} \mathrm{C}$ for $24-48 \mathrm{~h}$ and the results of color change were recorded as positive or negative. A control using $0.1 \mathrm{~mL}$ sterile water development of turbidity in culture tubes was recorded as the ability of isolates to grow at $10^{\circ} \mathrm{C}$ and $42^{\circ} \mathrm{C}$ and results were noted as positive or negative.

\section{Effect of $\mathrm{NaCl}$ Concentrations on Growth of Isolates}

The isolates were inoculated in MRS broth having different $\mathrm{NaCl}$ concentration $(2.0 \%$, $4.0 \%$ and $6.5 \%$ ) and incubated at $37^{\circ} \mathrm{C}$ for 24-48h. The culture tubes were observed for the presence or absence of growth.

\section{Biochemical Characterization of Isolates}

\section{Catalase Test}

The test was performed in order to determine the ability of the isolated cultures to degrade the hydrogen peroxide by producing the enzyme catalase. The test was carried out as the slide method, using an inoculating needle $\mathrm{f}$ or this, culture from a typical colony was placed onto a clean grease-free glass slide and drop of $3 \%$ hydrogen peroxide solution was added onto the culture and closely observed for the evolution of bubbles. The production of bubbles indicated positive catalase reaction and was recorded

\section{Identification and Characterization of Lactobacillus Isolates}

The Gram reaction property and cell morphology of all the isolates were examined using standard staining procedure. The isolates were found to be purple colored 
Gram-positive rods (i.e., straight rods, irregular rods, rods with rounded ends) of varying sizes and arrangements such as rods in single, or in chains (2-5 cells), under oil immersion microscope After confirming the Gram positive character each isolate was further characterized for cell dimensions using micrometry. These preliminary results as inoculum was used to compare the color change. Sugars used to determine the fermentation profile of Lactobacilli isolates were arabinose, cellobiose, fructose, galactose, lactose, maltose, mannitol, mannose, melibiose, raffinose, rhamnose, trehalose, salicin, sorbitol, sucrose and xylose. The cultures were identified based on the pattern of sugar utilization.

\section{Results and Discussion}

\section{Isolation of Lactobacilli from Dahi from Nearby Vicinity}

Out of several colonies developed on agar plates, based on colonial morphology (i.e., color, size, margin and shape of the colony) such as white, greyish white or cream color, size varying from $0.5-2.3 \mathrm{~mm}$ in diameters, with entire or undulate margins were picked up after plating $1 \mathrm{~mL}$ of sample that was previously enriched in $9 \mathrm{~mL}$ of Lactobacillus selection MRS broth for $24 \mathrm{~h}$ at $37^{\circ} \mathrm{C}$. The sub-culturing of isolates was done 3-4 times in MRS agar by incubating at $3{ }^{\circ} \mathrm{C}$ for 24 $48 \mathrm{~h}$. Finally, the well isolated colonies were streaked on the solidified Petri plates of Lactobacillus selection MRS agar with inoculating loop incubated aerobically at $37^{\circ} \mathrm{Cfor} 48 \mathrm{~h}$ for further identification and characterization based on different physiological and biochemical tests used routinely in microbial taxonomy.

\section{Biochemical Characterization of Lactobacilli}

\section{Catalase Production}

Catalase, an extracellular enzyme secreted by several microorganisms, helps in degradation of hydrogen peroxide produced during carbohydrates utilization for energy production, thereby its presence or absence in a microbial cell can be used as a significant indicated that the isolates could belong to the Lactobacilli group and paved the way for further characterization through physiological and biochemical means for confirmation.

\section{Physiological Characterization}

\section{Growth at $10^{\circ} \mathrm{C}$ and $42^{\circ} \mathrm{C}$}

The isolated Lactobacilli cultures were assessed for their growth at two different temperatures (i.e., $10^{\circ} \mathrm{C}$ and $42^{\circ} \mathrm{C}$ ). For this, cultures were incubated in MRS broth at $10^{\circ} \mathrm{C}$ for 7 days and the turbidity in broth was observed as an indication of microbial growth. The isolates showed good turbidity except that of 30 isolates i.e., Lactobacillus acidophilus, Lactobacillus bulgaricus, Lactobacillus lactis where no growth was observed in terms of turbidity. On the other hand, isolates were also incubated at $42^{\circ} \mathrm{C}$ for 24 to $48 \mathrm{~h}$ and turbidity was observed in tubes containing isolates Lactobacillus acidophilus, Lactobacillus bulgaricus, Lactobacillus lactis.

The other Lactobacilli could not grow at the elevated temperature of $42^{\circ} \mathrm{C}$. Hence, it can be concluded form that $37^{\circ} \mathrm{C}$ is the optimum temperature for all the isolates and few of these could either survive or grow at $10^{\circ} \mathrm{C} / 42^{\circ} \mathrm{C}$ or at both the temperatures away from the optimum.

\section{Effect of $\mathrm{NaCl}$}

The other physiological parameter for growth of a cell is the requirement of sodium chloride as the physiological saline prevents the cell from osmotic shock. For this, isolated Lactobacilli cultures were incubated in MRS broth at $37^{\circ} \mathrm{C}$ for $24 \mathrm{~h}$ to 
assess the effect of different $\mathrm{NaCl}$ concentrations (i.e., $2.0 \%, 4.0 \%$, and $6.5 \%$ ) in terms of turbidity, as an indication of microbial growth. At the $\mathrm{NaCl}$ concentration of $2.0 \%$, the growth was observed in all the Lactobacilli isolates. With an increase in $\mathrm{NaCl}$ from $2 \%$ to $4 \%$, turbidity diagnostic tool.

The catalase is involved in catalyzing the breakdown of toxic hydrogen peroxide to produce molecular oxygen that generates vigorously while producing effervescence, when a microbial culture is mixed with an equal volume of $3 \%$ solution of hydrogen peroxide. Absence of effervescence is taken as indicative as negative for catalase enzyme production. In the present study, all the isolates were found to be catalase negative. These results obtained for catalase further support the identification of isolates as Lactobacilli and pave the way in further characterization of the isolates and are in agreement with.

\section{Gas from Glucose}

The microorganisms use carbohydrates in a different pattern depending on their enzyme complement. In fermentation, substrates such as carbohydrates and alcohols undergo anaerobic dissimilation and produce organic acids that may be accompanied by the production of gases such as hydrogen or carbon-dioxide. Therefore, all the Lactobacilli were subjected to glucose fermentation test in order to see the production of gas.

It was observed from produced gas in broth containing glucose as the sole source of carbon while other isolates could not produce any gas as shown by a hollow space in the inverted Durham's tubes and, therefore, resulted as negative for gas production from glucose. Thus, the above isolates showed fermentation of glucose in the medium for their growth. These variations in results were also reported (10, 11, 12).

\section{Citrate Utilization Test}

For further characterization and identification, all the isolates were subjected for their potential to utilize citrate as the sole carbon source. Further, it also attributes to the better technological property of the was observed only in three isolates Lactobacillus acidophilus, Lactobacillus bulgaricus, Lactobacillus lactis. The growth pattern at $4 \% \mathrm{NaCl}$ concentration was also reported and concluded wide variation in growth of Lactobacilli cultures. At $6.5 \% \mathrm{NaCl}$ concentration, not a single isolate could show growth as indicated in basal media with different sugar discs. In total, 16 sugars were used for conformational identification of Lactobacilli and these were: arbinose, cellobiose, fructose, galactose, lactose, maltose, manitol, mannose, melibiose, raffinose, rhamnose, salicin, sorbitol, sucrose, trehalose and xylose. Different isolates showed different types of sugar utilization patterns where some tubes containing isolates and sugar turned yellow where as the other remained brown colored, indicating the positive and negative tests, respectively for sugar fermentation. When these sugar utilization patterns were compared with those given for Lactobacillus species in the Bergey's Manual of Determinative Bacteriology, the isolates were tentatively identified as L.acidophilus, L.bulgaricus, L. lactis. Hence, nine different species within Lactobacillus genera in the dahi sample obtained from rural and urban locations were confirmed in the present results.

\section{Carbohydrate Fermentation Pattern of Isolated Lactobacilli Cultures}

For accounting the sugar utilization pattern 
of the isolates suspected to be the Lactobacilli after their growth on
Lactobacillus selection MRS agar, the sugar utilization tests were performed using CHL.

Table.1 Morphological, Physiological and Biochemical characterization of Lactobacillus spp

\begin{tabular}{|c|c|c|c|}
\hline Characteristics & Strain I & Strain II & $\begin{array}{l}\text { Lactobacillus } \\
\text { acidophilus } \\
\text { Characteristics } \\
\text { (Bergy's Manual) }\end{array}$ \\
\hline \multicolumn{4}{|l|}{$\begin{array}{l}\text { Morphological } \\
\text { Characterization }\end{array}$} \\
\hline Colour & Cream-white & Cream-white & Cream-white \\
\hline Shape & circular & circular & Circular \\
\hline Size & $0.6 \mu \mathrm{m}$ & $0.5 \mu \mathrm{m}$ & $0.5-0.8 \mu \mathrm{m}$ \\
\hline Motility & Non-motile & Non-motile & Non-motile \\
\hline Gram reaction & Positive & Positive & Positive \\
\hline Shape & rod & Rod & Rod \\
\hline \multicolumn{4}{|c|}{$\begin{array}{l}\text { Physiological } \\
\text { characterization }\end{array}$} \\
\hline \multicolumn{4}{|c|}{$\begin{array}{l}\text { Growth at different } \\
\text { temperature }\end{array}$} \\
\hline $15-20^{\circ} \mathrm{C}$ & - & - & - \\
\hline $30^{\circ} \mathrm{C}$ & + & + & + \\
\hline $35^{\circ} \mathrm{C}$ & + & + & + \\
\hline $37^{\circ} \mathrm{C}$ & + & + & + \\
\hline \multicolumn{4}{|c|}{ Oxygen requirement } \\
\hline Aerobic & + & + & + \\
\hline Anaerobic & - & - & - \\
\hline Microaerophilic & + & + & + \\
\hline \multicolumn{4}{|l|}{$\begin{array}{l}\text { Biochemical } \\
\text { characterization }\end{array}$} \\
\hline Indole & - & - & - \\
\hline Methyl red & - & - & - \\
\hline Voges proskauer & - & - & - \\
\hline Citrate utilization & - & - & - \\
\hline Urease & - & - & - \\
\hline Triple sugar iron & - & - & - \\
\hline Nitrate reduction & - & - & - \\
\hline Catalase & - & - & - \\
\hline Oxidase & - & - & - \\
\hline
\end{tabular}


Table. 2 Carbohydrate Fermentation of Lactobacillus spp

\begin{tabular}{|l|c|c|c|}
\hline \multicolumn{1}{|c|}{ Sugars } & Strain I & Strain II & $\begin{array}{c}\text { Lactobacillus acidophilus } \\
\text { Characteristics (Bergy's manual) }\end{array}$ \\
\hline Dextrose & + & + & + \\
\hline Fructose & + & + & + \\
\hline Galactose & + & + & + \\
\hline Glucose & + & + & + \\
\hline Lactose & + & + & + \\
\hline Maltose & + & + & + \\
\hline Mannitol & + & + & + \\
\hline Sucrose & + & + & + \\
\hline Xylose & - & - & - \\
\hline
\end{tabular}

Morphological characterization of Lactobacillus acidophilus

a.

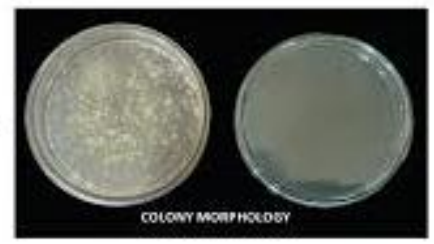

b.

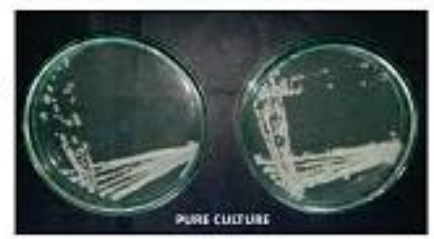

Gram Staining

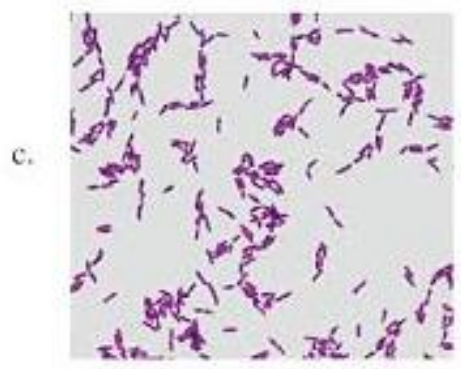

In conclusion, from dahi, a total of 3 Lactobacillus isolates were distributed among nine species and identified as, $L$. acidophilus, L. bulgaricus, L. lactis, where L. acidophilus, was the most prevalent. It can be stated that L. acidophilus isolated from traditional Indian dairy product (dahi) could be exploited as a probiotic after investigating its beneficial characteristics. product as citrate utilization leads to a better flavor production in fermented milk production. Certain bacteria utilize citrate with the help of enzyme citrate permease and citrate-producing diacetyl, a flavoring 
compound as end product. Following incubation on Simmon's citrate agar, citratepositive cultures were identified by the presence of growth on the surface of slant, accompanied by blue coloration whereas negative cultures did not show any growth and medium remained green.

\section{References}

1.Puniya, M., K. P. S. Sangu, A. Bhardwaj, et al. Journal of Research in Antimicrobials. 2012. 1, 001-011p.

2.Dhewa, T., Lactic Acid Bacteria as Probiotics: Applications and Safety Issues. Germany. LAMBERT Academic Publishing. 2011.

3.Isolauri, E., P. V. Kirjavainen and S. Salminen. Gut. 2002. 50. 54-59p.

4.Dicks, L. M. T., and M. Botes. Beneficial Microbes. 2010. 1. 11-29p.

5.Dhewa, T., V. Bajpai, R. K. Saxena, et al. International Journal of Probiotics and Prebiotics. 2010. 5(1). 45-52p.

6.Dhewa, T., S. Pant and V. Mishra. Journal of Food Science and Technology. 2011. DOI 10.1007/s13197-011-0457-2.

7.Roberfroid,M. B. American Journal of
Clinical Nutrition. 1998. 73. 406-409p.

8.Stanton, C., G. Gardiner, H. Meehan, et al. American Journal of Clinical Nutrition. 2001. 73. 4765-4835p.

9.Dhewa, T., and N. Goyal. The IUP Journal of Life Sciences. 2009. 3. 29-34p.

10.Tannock, G. W., K. Munro, H. J. M. Harmsen, et al. Applied Environmental Microbiology. 2000. 66. 2578-2588p.

12.Holt, J. G., N. R. Kreig, P. H. A. Sneath, et al. Bergey's Manual of Determinative Bacteriology. 2004.

13.Wang, J., X. Chen, W. Liu, et al. European Food stated that $L$. acidophilus isolated from traditional Research Technology. 2008. 15551561p.

14.Kaushik, J. K., A. Kumar, R. K. Duary, et al. PLoS one. 2009. 4(12). e8099 111p. 15. A. K. Puniya, S. Chaitanya, A. K. Tyagi, et al. Journal of Industrial Microbiology and Biotechnology. 2008. 35. 1223-1228p.

16.Holt, J.G., N.R. Krieg, P.H.A. Sneath, et al., Bergeys Manual of Determinative Bacteriology. 1994. USA. 9th Edn.11. F. Chaucheyras-Durand and H. Durand. Beneficial Microbes. 2010.1. 3-9p.

\section{How to cite this article:}

Kavitha, P., D. Sindhuja and Banumathi, M. 2016. Isolation and Biochemical Characterization of Lactobacillus species Isolated from Dahi. Int.J.Curr.Microbiol.App.Sci. 5(4): 1042-1049. doi: http://dx.doi.org/10.20546/ijcmas.2016.504.119 